\title{
Contributions to a Conceit
}

Humankind has always thought that it is special. Even from an early age we humans are instinctively sure of our superiority. It was certainly inconceivable to me, at age four or so, that my six-year old sister could be right about anything, so when she casually informed me that I was "just an animal," I confidently dismissed her pronouncement as mere rhetoric. Or I probably would have, if I had known what rhetoric was. Still, it was certainly a disquieting thought that there was no fundamental difference between humans and animals.

There is a long history of thinkers great and small trying to identify one salient characteristic in which the human species is somehow superior to the rest of the world's fauna. Such is the conceit of humankind that we remain irrationally certain that some such characteristic actually exists. Aristotle probably started it with a wholly untested assertion that laughter is unique to humans; but behaviors that are at least laughter-like have now been observed in other primates, and (arguably) even in rats. From Aristotle until the Dark Ages, though, there was no real debate in western cultures. The Bible (or the great book of almost any other religion) simply asserted the superiority of man over beast. Once the "Age of Reason" set in, however, it was necessary to demonstrate some way in which humans actually were superior to animals, and the literature is thereafter littered with failed ideas.

First, it was asserted that the use of language was the key distinguishing feature of mankind. Then, around the middle of the 20th century we discovered that other creatures, from whales down to honeybees, had also figured out the trick, using either sound or sign language. Prairie dogs and chimpanzees are all in on it, too, and deep-sea squids even communicate in color, flashing signals to one another using light-emitting skin cells called chromatophores.

So then the emphasis shifted from a distinction based on the literary skills of humankind to its technological capabilities, and the focus was on mankind's purportedly unique abilities with tools. Alas, observational science has debunked this myth of superiority, too. Various birds and primates have demonstrated the ability to make and use tools. Woodpecker finches, being finches rather than woodpeckers, are not naturally adapted to peck wood, so they cut cactus spines to just the

right size for use in prying tasty grubs out of tree limbs. Green herons have recently been observed to catch fish with the use of bait; and, somehow more sinisterly, chimpanzees have been spotted in the wild, using rudimentary spears to kill bush

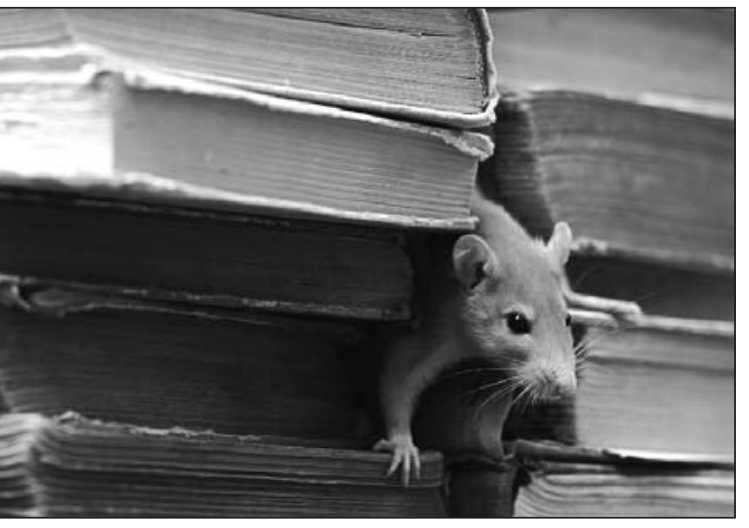

babies for food. Evidently tool use is not the distinction that it was once thought to be. Not even weapon use.

So my first proposal is this: Humans differ from the other animals in their ability, indeed their need, to use energy that they do not generate metabolically within their own bodies. All of the tools used by other species are powered only by the animal itself, but we get much of our

\section{Is there some higher function than thermodynamics that might distinguish humans from mere "animals?"}

energy elsewhere. We have accessed chemical energy starting from the discovery of fire, and we have made more and more sophisticated use of this basic source since then. We have used the metabolic energy of other animals to pull plows and wagons. We have converted the kinetic energy of wind and water to do our work. We have even enslaved members of our own species to use their energy where other sources were not available or could not be adapted to the necessary tasks. And today we use all sorts of other sources of energy so we can avoid, to whatever extent we can achieve, actually doing any work ourselves.

Our need for energy seems to have dominated our sense of ethics throughout history, too. When the need was great enough, even clear thinkers and revolu- tionary freedom fighters like Thomas Jefferson and George Washington saw no contradiction in owning slaves to assist in maintaining their estates. It was only when other means became available to get the work done that a debate could occur about the moral acceptability of slavery, and the debate lasted longer where slaves were harder to replace. Today we are still willing to damage the very atmosphere in which we all live in order to get at some energy, and let us not even try to summarize the political distortions and security risks that we can tolerate in order to have access to oil.

Maybe it is a good thing that all the other animals only use their own energy.... It has been suggested that a sense of morality or altruism is the distinguishing feature of humankind, but lately altruistic acts have also been observed in animals, even in vampire bats, which are evidently horribly typecast. If they used external energy sources, you can bet that the animals would pretty quickly lose whatever moral compass they might already possess in order to ensure their own supply of energy.

But wait.... It only requires one counterexample to disprove a hypothesis, and the animal kingdom contains several species of slavemaker ants. These formic conquistadors occupy the colonies of other species of ants, making them feed their new masters and do all of the scut work in the nest. It is not clear whether the slavemakers add any value by providing "administrative functions" as in so many human societies, but the slaves even carry them along during the colony relocations. So my hypothesis fails: humans are not alone in relying on external energy sources.

Is there some higher function than thermodynamics that might distinguish humans from mere "animals?" If not laughter, language, tools, altruism, or energy, what is there that can set humankind apart from the "lower animals?" Perhaps the real issue, if there is one- the one irreducible, uniquely human characteristic - is the use of artificial materials; so enjoy yourselves at the MRS meeting, as you bask in the glory of being at the source of the one still-unfalsified distinction between man and beast. Or you could just laugh about it, and conclude that the real distinguishing feature is that we suffer from conceits about distinguishing features.

Alex KING 